\title{
A case study on deterioration assessment and rehabilitation of fire damaged reinforced concrete structure
}

\author{
Ojha P N, Brijesh Singh*, Adarsh Kumar N S, Abhishek Singh, Vikas Patel
}

\begin{abstract}
National Council for Cement and Building Materials, India.
* Corresponding Author: brijeshsehwagiitr96@gmail.com
\end{abstract}

Received: 02-02-2021

Accepted: 27-05-2021

\begin{abstract}
Fire is one of the most severe hazards that building structures may experience during their lifetime. A fire spread to the whole structure can cause unexpected damages to the structural elements. Mainly, the building type is crucially important for the type and the level of damage to the building because of the fire. Post fire investigation of damaged structure is required to determine the extent of damage to concrete elements and to work out system of effective repair/rehabilitation measures to maintain the structural integrity of fire effected structural components. The paper covers in brief the strength and durability study on fire damaged building in Delhi, India. The study reports the extent of fire damage. Optical Microscopy (OM), X-Ray Diffraction (XRD) and Deferential Thermal Analysis (DTA) studies were carried out on the sample concrete cores extracted from different identified portions of the fire exposed concrete are highlighted in this paper. Extent of damage occurred in the Reinforced Cement Concrete (RCC) i.e. RCC columns/beams/slabs are described based on the detailed evaluation by various Non-Destructive Evaluation Techniques covering Cover study \& Ultrasonic Pulse Velocity (UPV) testing. Repair and remedial measures required for restoration and strengthening of the fire affected RCC columns/beams/slabs using indigenously available repair materials and techniques are also highlighted in this paper.
\end{abstract}

Key words: Fire Damage, Field Investigation, Lab Investigation, X-Ray Diffraction, Differential Thermal Analysis.

\section{Introduction}

Concrete is being a heterogeneous material, consisting of a composite of cement gel, aggregate and steel (or other) reinforcement. Each of these components has a different reaction to thermal exposures in itself, and the behavior of the composite system in fire is not easy to define or model. Concrete during high temperature event has a complex behavior due to the differences in coefficient of thermal expansion of each constitution. Several factors that affect the fire resistance of concrete are concrete strength, moisture content, concrete density, and aggregate type. Steel reinforcement if protected by the minimum cover specified by the code it is expected that the effect of high temperature on the reinforcement bars will be negligible. $60 \%$ to $70 \%$ per volume of any concrete mixture is coarse aggregate; therefore, change in the concrete proprieties is mainly affected by the type of coarse aggregates used in the mixture. Three types of aggregates are commonly used in the construction industry; carbonate, siliceous, and lightweight. The specific heat and thermal conductivity of concrete are greatly affected by aggregate type (Pathak et al., 2013). To determine the extent of fire damage occurred in effected RCC Columns /Beams/Slabs of the building field assessment covering Quality assessment using UPV testing, measurement of concrete cover depth and carbonation depth, followed by laboratory scale assessment of residual strength of concrete, OM study, XRD study and DTA study is reported in this paper. Highlights on suitable materials \& techniques to carryout repair and strengthening of the RCC Columns/Beams/Slabs are also briefly described in this paper. Extensive studies had been carried out on the behavior of Reinforced Concrete structures exposed to fire and repair \& rehabilitation of such structures in India and abroad. The technical papers covering different aspects of damage assessment, repair and rehabilitation of fire damaged structures are reported by the authors (Pathak et al., 2013; Yehia \& Kashwani, 2013; 
Sangluaia et al., 2013; Ingham, 2007; Bailey, 2002; FIB, 2008; Fletcher et al., 2007; Capote et al., 2006; Usmani et al., 2006; Buchanan and Abu, 2017; Georgali and Tsakiridis, 2005; Hertz and Sørensen, 2005; Ali et al., 2004).

In the literature, the behavior of ordinary concrete which is not fireproof or containing fine grained component than cement grains with elevated temperature has been sorted in different ways but following the similar stages. The free water inside the concrete starts to evaporate with increasing temperature. Above $150^{\circ} \mathrm{C}$, the water bound the hydrated calcium silicate has been released and reaches its peak about $270^{\circ} \mathrm{C}$. Inertial stress development has occurred in this initial stage. Dehydration of the matrix and relative thermal expansions of the aggregates in the concrete lead to microcracks in the material after $300^{\circ} \mathrm{C}$. This phenomenon leads to decrease in the strength and elasticity modulus of the material. If the concrete is exposed less than $300^{\circ} \mathrm{C}$, it can absorb the moisture from the air and recover. However, after the formation of microcracks, the strength loss is not recoverable. Therefore, it is recommended to remove the material that exposed above $300^{\circ} \mathrm{C}$. Between $400-600^{\circ} \mathrm{C}$, the calcium hydroxide decomposes into calcium oxide and water, and then water evaporates, and shrinkage occurs in the matrix. The most severe decrease in the strength of the concrete occurs in this range. After the fire, the calcium oxide reacts with the cooling water and the moisture in the air that forms new calcium hydroxide. This reaction causes the expansion of the cracks in the concrete and further decrease (about 20\%) in the strength of the material. The hydrated calcium silicate decomposes after $600^{\circ} \mathrm{C}$, and the concrete can be crumbled to gravel by the finger after $800^{\circ} \mathrm{C}$.Then, feldspar melts and remaining minerals of the cement turns into a glass phase above $1150^{\circ} \mathrm{C}(\mathrm{Hertz}, 2005)$.

The strength of the concrete that is fully hydrated may increase within the first $100-200^{\circ} \mathrm{C}$. However, this increase should not be considered in the design stage because of the dependency of the age of the concrete and condition of the material (Hertz, 2005). Studies done in past indicated that high strength concrete had higher residual strength, although the strength of high strength concrete decreased more sharply than the normal-strength concrete after exposure to high temperature. The porosity and pore size distribution of the concrete were investigated using mercury intrusion porosimetry. Study indicated that the changes in pore structure can be used to indicate the degradation of mechanical property of high strength concrete subjected to high temperature (Chan et al., 1999). A brief outline of the changes that take place in concrete with increasing temperature is given below (Schneider, 1988; Stawiski, 2005; ACI, 1997):

1. $30-110^{\circ} \mathrm{C}$ : The evaporable water and a part of the bound water escapes. It is generally considered that the evaporable water is completely eliminated at $120^{\circ} \mathrm{C}$.

2. $110-180^{\circ} \mathrm{C}$ : The decomposition of gypsum (with a double Endo-thermal reaction, the decomposition of ettringite and the loss of water from part of the Carbo-aluminate hydrates take place.

3. $180-350^{\circ} \mathrm{C}$ : The loss of bound water from the decomposition of the C-S-H and Carboaluminate hydrates take place.

4. $450-550^{\circ} \mathrm{C}$ : Dehydroxylation of the portlandite (calcium hydroxide).

5. $700-900^{\circ} \mathrm{C}$ : De-carbonation of calcium carbonate. All the calcium hydroxide is converted to calcium oxide and the C-S-H converts to an anhydrous calcium aluminum silicate. These reactions cause a decrease in volume which leads to cracking in the paste.

6. Above $900^{\circ} \mathrm{C}$ : Further decomposition of aggregates. Concrete starts burning. The significant loss in strength of reinforcing bar is observed at high temperature resulting into decrease in stiffness of structural members which is responsible for excessive residual deflections. However, recovery of yield strength after cooling is generally complete for temperatures up to $450^{\circ} \mathrm{C}$ for cold drawn bars and $600^{\circ} \mathrm{C}$ for hot rolled drawn bars. Above these temperatures, there will be a loss in yield strength after cooling. 
The deterioration of the compressive strength of the concrete with temperature can be clarified with physical and chemical changes in the concrete with elevated temperature. The physical and chemical changes can be sorted by changes in water content, hydration products, pore structure, microstructure and spalling. The tendency of these changes in the concrete are affected from many parameters: compression strength of the concrete, moisture content, density of the concrete, thermo-physical properties of concrete, external load, pre-stress, temperature gradient, temperature distribution on the structural elements, dimensions of the elements, reinforcement ratio, existing of fibers, aggregate and type of the cement additives, etc.

Reinforced concrete structures which are damaged due to fire can be rehabilitated and strengthened by using various retrofitting methods. Different structural and non-structural members of fire damaged structure are subjected to different repair mechanisms depending upon extent of damages. For example, strengthening of fire damaged reinforced concrete beams and columns with fiber-reinforced polymer (FRP) sheets and use of near-surface mounted carbon FRP rods for repair of damaged RC slabs are one of the most popular retrofitting methods nowadays. They are sufficiently effective to restore the structural functions of the damaged structural components (ACI, 1986; ISO, 1975; CEN, 2003).

\section{Investigation}

In order to take up the research project on fire damaged structures, during the preliminary site investigation it was observed that the fire has occurred at the fifth floor room of the building and its fumes/gases escaped through the duct opening in the roof slab to mezzanine floor at the top. The spalling of plaster from roof slab, beams and columns had occurred at several places (refer Fig. 1-2). No documents or drawings other than a basic plan view of the arrangement of rooms on the floors was available. No details regarding the structural design or mix design of concrete were available. Accordingly the authors decided to categorize the various investigation studies in two parts i.e. field investigation and laboratory investigation. The field investigation covered (i) determination of Quality of concrete using UPV testing technique as per IS: 13311 (Part - I) 1992, (ii) Concrete cover study and (iii) extraction of concrete cores samples from identified members for Carbonation study at site and to further carry out the laboratory investigation on concrete cores, which covered (a) Determination of equivalent cube compressive strength of concrete core as per IS 456 (2000) \& IS:516(1959) (b) Chemical analysis of hardened concrete to determine $\mathrm{pH}$ value, chloride content and Sulphate content.

\subsection{Field Investigation}

\subsubsection{Observations on Change in Colour of Concrete}

When concrete gets heated to elevated temperatures, a gradual change in colour of the concrete occurs depending on the temperature range it is exposed to FIB (2008) gives guidance regarding the probable colour change in concrete depending on the exposure to elevated temperatures. Change in colour of concrete to pink was found in some of the beams and columns close to the room where fire was first detected. The depth up to which change in colour of concrete had occurred was also noted on the extracted concrete cores. At locations close to the room where fire was first detected and duration to exposure to fire was more, the maximum depth up to which change in colour of concrete had occurred was found to be about $12-20 \mathrm{~mm}$. At other locations the colour change was visible only up to about $10 \mathrm{~mm}$ depth. The color of the cement mortar plaster had changed to light pinkish grey.

\subsubsection{Quality of Concrete using UPV testing technique as per IS 13311 (1992)}

Quality of concrete was assessed by UPV testing (using Portable Ultrasonic Non-Destructive Digital Indicating Tester-PUNDIT) on the selected locations of RCC columns/Beams. 
Measurements were taken by direct method (cross-probing) as shown in fig.3. Based on Ultrasonic Pulse Velocity obtained, the overall quality of concrete was graded as 'Good'.

UPV measurements were also taken by cross probing technique using $150 \mathrm{kHz}$ transducers on some of the extracted concrete cores taken from the fire damaged portion. The results indicated that the UPV values near the surface region of concrete, where colour change was visible and the effect of exposure to elevated temperatures was likely to be more, typically had lower UPV values as compared to the concrete in the inner regions but all the values were in Good Quality Grading as per IS: 13311 (1992).

Table 1. UPV values on extracted concrete cores

\begin{tabular}{|c|c|}
\hline Depth & UPV values by cross probing on concrete core \\
\hline \hline 20 & 3.50 \\
\hline 40 & 3.59 \\
\hline 60 & 4.20 \\
\hline 80 & 4.25 \\
\hline 100 & 4.35 \\
\hline 120 & 4.41 \\
\hline
\end{tabular}

\subsubsection{Concrete cover study}

The concrete cover study carried out by the Ferro-scanning Technique (using Ferro Scanner) to identify the thickness of concrete cover provided on the various identified locations of the fire damaged area of Building. The observations were made on total 8 numbers identified RCC members and for each member four measurements were taken. The results indicated that the average concrete cover was varying from $35 \mathrm{~mm}$ to $45 \mathrm{~mm}$ in Slabs, $35 \mathrm{~mm}$ in Beams and varying from $35 \mathrm{~mm}$ to $42 \mathrm{~mm}$ in Columns. The thickness of cement mortar plaster on various Reinforced Cement Concrete members was varying from $15 \mathrm{~mm}$ to $20 \mathrm{~mm}$ as observed during the field investigation.

\subsubsection{Carbonation study}

Carbonation study was carried out by spraying a pH indicator (solutions of $1 \%$ phenolphthalein in 70\%ethyl alcohol) on freshly extracted concrete core samples from identified representative members. The depth of carbonation in different samples was found to be varying from $0 \mathrm{~mm}$ to $10 \mathrm{~mm}$.

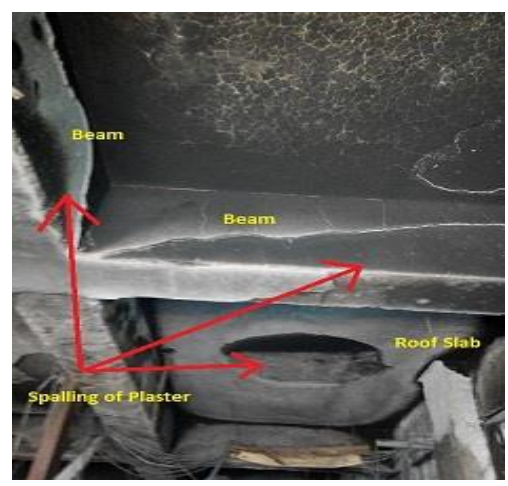

Fig. 1. Spalling of Plaster in Beams \& Slabs

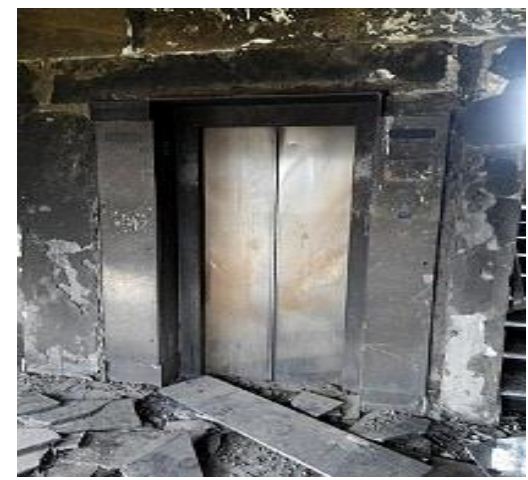

Fig. 2. View of lift lobby in fire damaged area

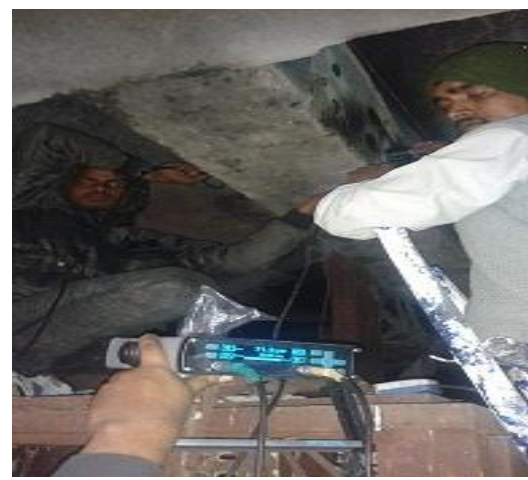

Fig. 3. UPV Measurement being recorded 


\subsection{Laboratory Investigation}

\subsubsection{Concrete Core Extraction and Testing}

In order to ascertain the effect of fire damage, if any, on the strength of concrete, cores which were of sufficient length were tested. The equivalent cube compressive strength assessment results of concrete core samples extracted from various Reinforced Cement Concrete members in fire damaged area were found to be satisfying the M25 grade of concrete, which was used in construction of building. Strength of the cores extracted from the vicinity of the area where fire was first detected is found to be slightly lower compared to other locations not subjected to fire by about 5 to 10 percent indicating less impact of fire on the RCC components of the structure.

\subsubsection{Chemical analysis study of concrete powder}

For carrying out the chemical analysis of hardened concrete, few representative concrete cores samples from identified location were sliced in three layers i.e. $(0 \mathrm{~mm}-20 \mathrm{~mm}),(20 \mathrm{~mm}-40 \mathrm{~mm})$ \& $(40 \mathrm{~mm}-60 \mathrm{~mm})$ from the exposed surface of the identified RCC member and further grinded to powder. The Chloride Test results of concrete powder shown that, chloride content in various samples was $0.12 \mathrm{~kg} / \mathrm{m}^{3}$ which were within the permissible limit of $0.60 \mathrm{~kg} / \mathrm{m}^{3}$ for RCC as prescribed in Table 7 of IS: 456 - 2000. The Sulphate content in various samples was varying from $1.44 \%$ to $2.46 \%$ which was within the permissible limit of $4 \%$ (As per clause-8.2.5.3 of IS: 456-2000). The $\mathrm{pH}$ values of the various representative concrete samples were found to be varying from 12.43 to 12.63 .

\subsubsection{Optical Microscopy (OM) Study}

The petrographic studies had been carried out on three concrete core samples from identified locations of RCC Column C32, Slab SI \& Slab S6 (Refer fig. 4-7) under Stereoscopic Microscope (NIKON SMZ-1500).

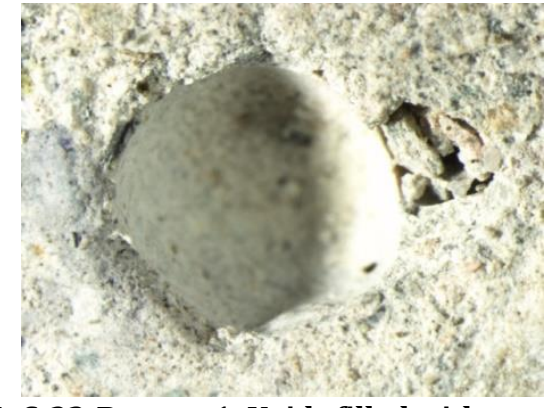

Fig. 4. C-32-Bottom-1: Voids filled with crystalline material

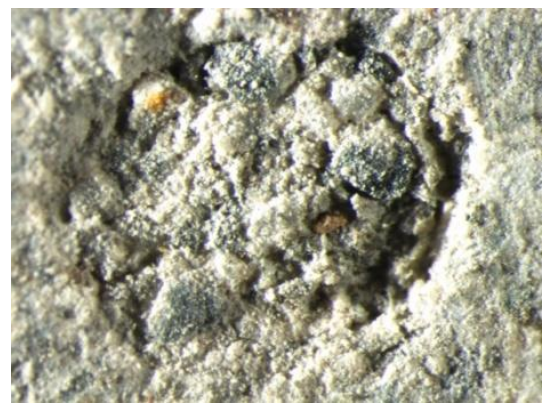

Fig. 6. S-6-Middle-3: Voids filled with crystalline material

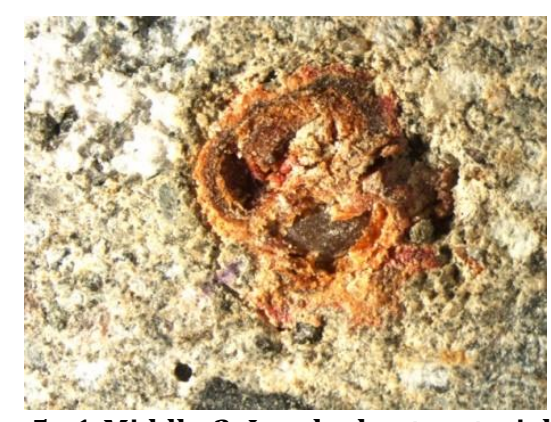

Fig. 5. -1-Middle-2: Leached out materials as observed in the sample

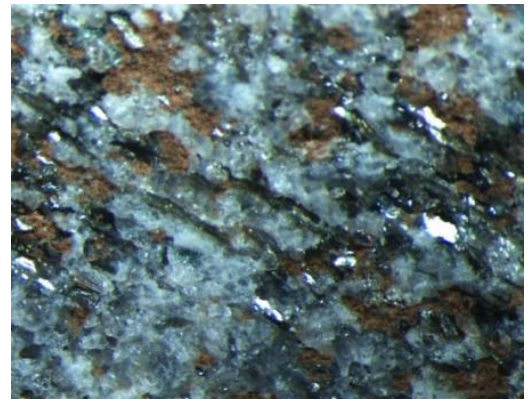

Fig. 7. S-6-Bottom-3: Stretching of coarse and fine aggregate due to temperature rise 
Three thin slices (up to $5 \mathrm{~mm}$ thick) from each of concrete core were drawn, one from top portion of core i.e. from exterior face /top of RCC member $(0-30 \mathrm{~mm})$, second from middle portion of the core $(30-60 \mathrm{~mm})$ and third from bottom portion of the core (beyond $60 \mathrm{~mm}$ ). The study was carried out to determine various micro structures, morphological features and pore distribution and development. Based on the results obtained on above parameters inferences were drawn to establish the deterioration development caused of the fire.

\subsubsection{X-Ray Diffraction (XRD)}

X-ray powder diffraction (XRD) is a rapid analytical technique primarily used for phase identification of a crystalline material. Crystalline substances act as three-dimensional diffraction gratings for X-ray wavelengths similar to the spacing of planes in a crystal lattice. Interaction of the incident rays with the sample produces constructive interference (and a diffracted ray) when conditions satisfy Bragg's Law $(\mathrm{n} \lambda=2 \mathrm{~d} \sin \theta)$, which relates the wavelength $(\lambda)$ of electromagnetic radiation to the diffraction angle $(\theta)$ and the lattice spacing (d) in a crystalline sample. The diffracted X-rays are then detected, processed and counted. Conversion of the diffraction peaks to d-spacings allows identification of the mineral because each mineral has a set of unique $d$-spacings. Typically, this is achieved by comparison of $d$-spacings with standard reference patterns. The X-Ray Diffraction (XRD) studies had been done on powder samples obtained after grinding of concrete core samples extracted from identified locations of Beam B-8 \& Slab S-1 of the fire damaged area. Major mineral phases present were Quartz, Calcite, Albite and Portlandite. Phlogopite, Dolomite, Muscovite, Kaolinite, Larnite etc were present in minor mineral phases. The XRD results indicated Quartz, Calcite and Dolomite were formed most likely due to rise in temperature of the concrete during fire. (Refer Table-2). Whereas, Kaolinite, Vaterite and Cordierite were formed due to rise in temperature.

Table 2. Relative abundance of various minerals as observed in XRD study on concrete samples of fire damaged structure

\begin{tabular}{|c|c|c|c|}
\hline \multirow{2}{*}{ Sl. No. } & \multirow{2}{*}{ Phase Identified } & \multicolumn{2}{|c|}{ Relative Abundance } \\
\hline & & Beam B8 & Slab S1 \\
\hline 1 & Quartz $\left[\mathrm{SiO}_{2}\right]$ & Major & Major \\
\hline 2 & Calcite $\left[\mathrm{CaCO}_{3}\right]$ & Major & Major \\
\hline 3 & Albite $\left[\mathrm{NaAlSi}_{3} \mathrm{O}_{8}\right]$ & Major & Major \\
\hline 4 & Portlandite $\left[\mathrm{Ca}(\mathrm{OH})_{2}\right]$ & Major & Major \\
\hline 5 & Dolomite $\left[\mathrm{CaMg}\left(\mathrm{CO}_{3}\right)_{2}\right]$ & Major & Minor \\
\hline 6 & Phlogopite $\left[\mathrm{K}_{2} \mathrm{Mg}_{6} \mathrm{Al}_{2} \mathrm{Si}_{6} \mathrm{O}_{24} \mathrm{H}_{4}\right]$ & Major & Minor \\
\hline 7 & Kaolinite $\left[\mathrm{Al}_{2} \mathrm{Si}_{2} \mathrm{O}_{5}(\mathrm{OH})_{4}\right]$ & Minor & Minor \\
\hline 8 & Larnite $\left[\mathrm{Ca}_{2} \mathrm{SiO}_{4}\right]$ & Minor & Minor \\
\hline 9 & Muscovite $\left[\left(\mathrm{K}_{0.77} \mathrm{Al}_{1.93}\left(\mathrm{Al}_{0.5} \mathrm{Si}_{3.5}\right) \mathrm{O}_{10}(\mathrm{OH})_{2}\right]\right.$ & Minor & Minor \\
\hline 10 & Vaterite $\left[\mathrm{CaCO}_{3}\right]$ & Minor & Minor \\
\hline 11 & Cordierite $\left[\mathrm{Mg}_{2} \mathrm{Al}_{4} \mathrm{Si}_{5} \mathrm{O}_{18}\right]$ & Minor & Minor \\
\hline
\end{tabular}

\subsubsection{Differential Thermal Analysis (DTA)}

The samples from identified locations covering Plaster from Beam B8 \& Beam B32 and sliced concrete cores in layers $(0-20 \mathrm{~mm}),(20-40 \mathrm{~mm}) \&(40-80 \mathrm{~mm})$ from Beam B8 and Slab S1, were grinded to powder passing 150 micron IS sieve. The Differential Thermal Analysis was carried out to assess weight loss corresponding to different temperatures. In sample of Beam-B8 Plaster, the total weight loss of 11.91 percent for $(0-20 \mathrm{~mm})$ depth up to a temperature of $1000^{\circ} \mathrm{C}$ from ambient@10C/minute. Graph for Beam B8 Plaster $(0-20 \mathrm{~mm})$ shown in fig. 8. In Beam-B32 Plaster, the total weight loss of 11.069 percent for $(0-20 \mathrm{~mm})$ depth up to a temperature of 
$1000^{\circ} \mathrm{C}$ from ambient@ $10^{\circ} \mathrm{C} /$ minute was observed. In sample from Slab S1, the total weight loss of 15.42 percent for $(0-20 \mathrm{~mm})$ depth, 15.16 percent for $(20-40 \mathrm{~mm})$ depth and 13.82 percent for $(40-80 \mathrm{~mm})$ depth up to a temperature of $1000^{\circ} \mathrm{C}$ from ambient@ $10^{\circ} \mathrm{C} /$ minute was observed. Graph for Slab S1 (0 - 20mm) is given in Fig. 9.

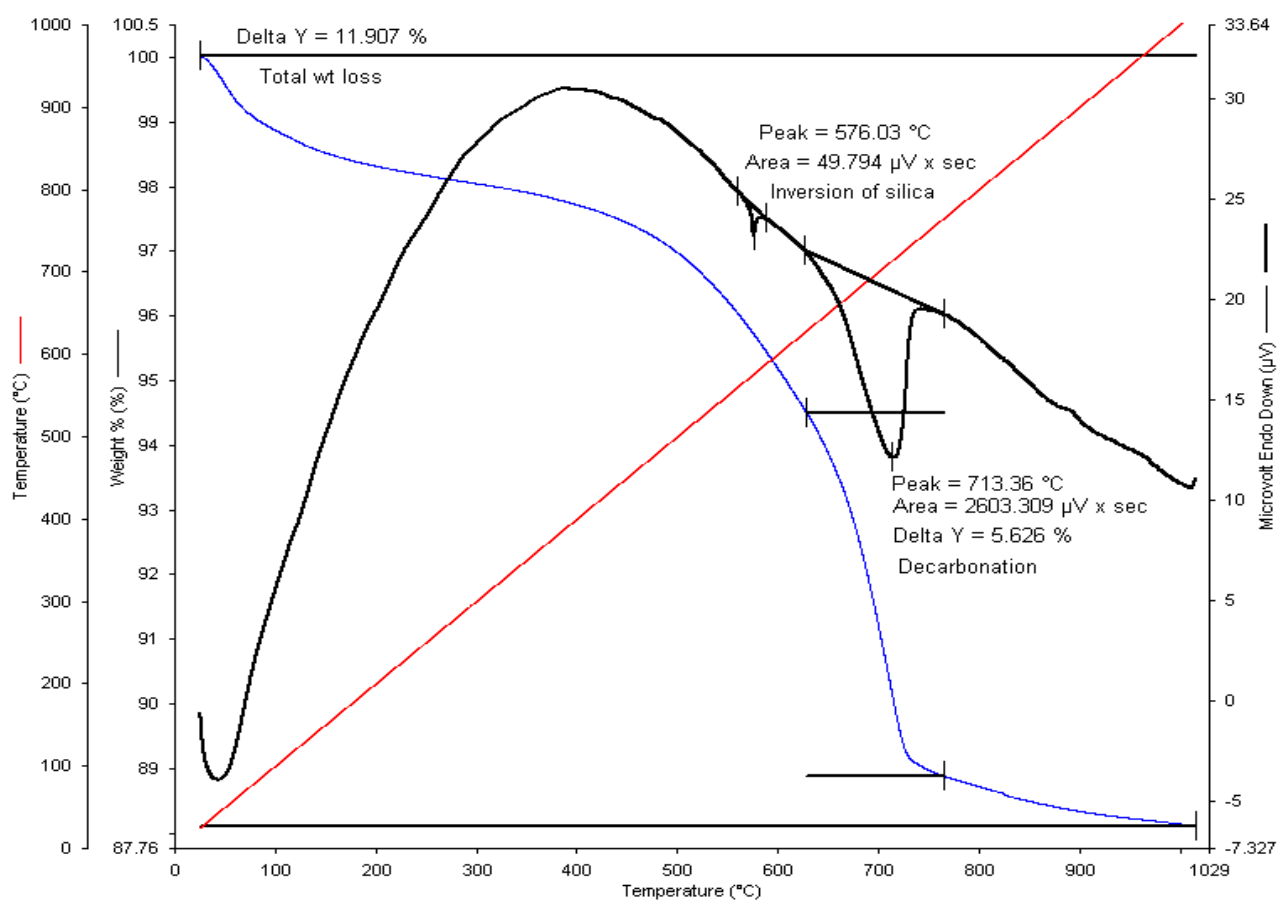

Fig. 8. Graphical Representations of study on plaster samples from Beam B8 of fire damaged area

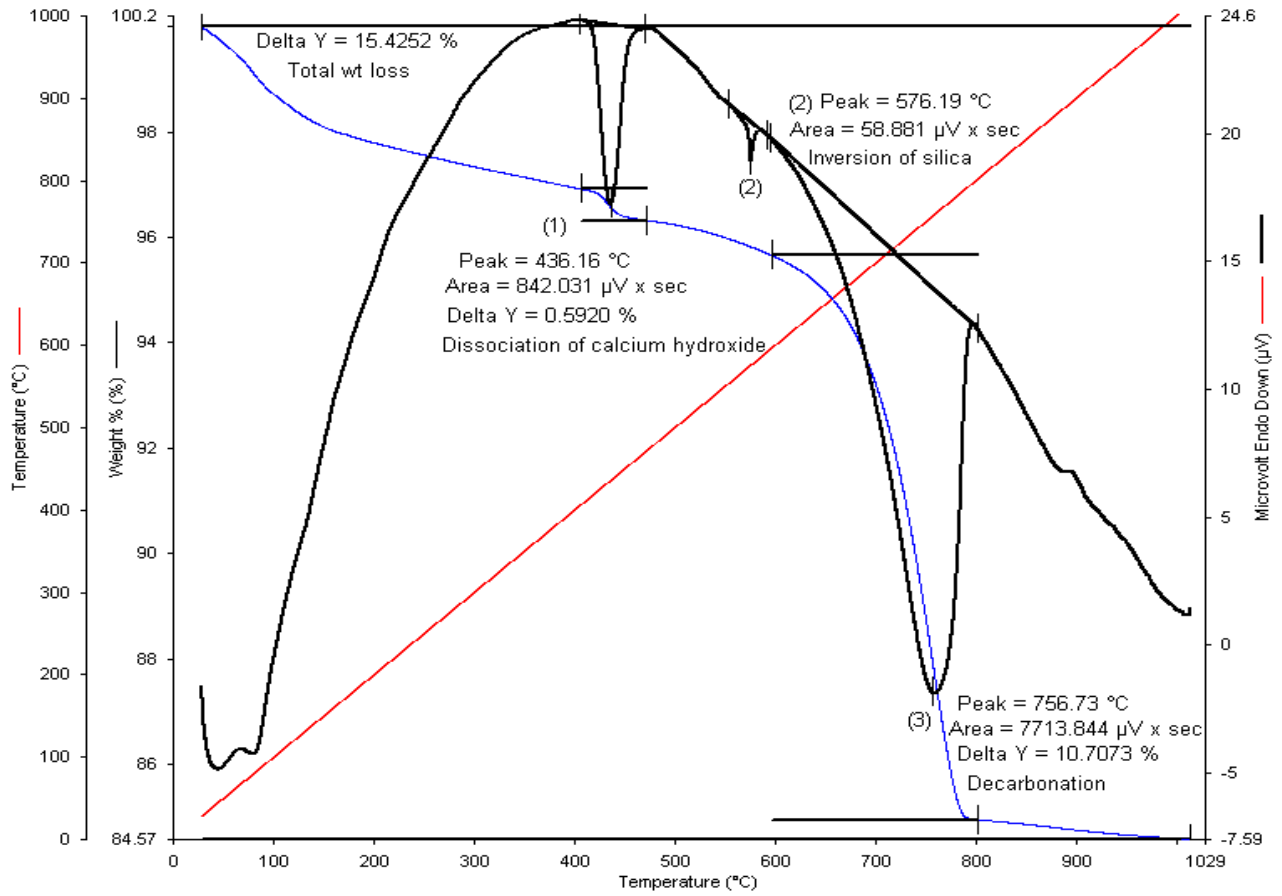

Fig. 9. Graphical Representations of study on concrete samples from Slab S1 of fire damaged area

In general, the results of DTA analysis done on all samples show that, the first endothermic peak occurred at around $430^{\circ} \mathrm{C}$ was due to dissociation of calcium hydroxide. Inversion of silica 
occurred at around $575^{\circ} \mathrm{C}$ and was represented by a small sharp endothermic peak. The third endothermic peak was occurred at around $750{ }^{\circ} \mathrm{C}$ due to decarbonation. Where effect of fire was negligible, peak due to dissociation of $\mathrm{Ca}(\mathrm{OH})_{2}$ was absent in the DTA curve at 0-5 mm depth whereas it was present in the DTA curves at greater depths. This indicates that at 0-5 $\mathrm{mm}$ depth, the peak was absent because of carbonation of concrete (measured depth of carbonation front was found to be maximum $10 \mathrm{~mm}$ ) and not due to exposure to elevated temperatures due to fire. As carbonation had not progressed beyond this depth, the peaks corresponding to dissociation of $\mathrm{Ca}(\mathrm{OH})_{2}$ were present in the DTA curves at greater depths.

\section{Discussion of results}

In order to determine the effect of the fire on the structural behavior of building the mechanical, chemical and microstructural properties of concrete after the fire needs to be compared with similar concrete not subjected to fire. The results needs to be compared with standard limits for chemical parameters and degradation in strength if any needs to evaluated through concrete core test results. The effect and extent of fire in the RCC member can also be evaluated through supplementary laboratory techniques such as Differential Thermal Analysis, X-Ray Diffraction, Optical Microscopy etc. Visual observation had indicated cracking \& spalling cement mortar plaster from various RCC Columns / Beams/ Slab of fire damaged room of Building. In the area outside fire damaged room no spalling of cement mortar plaster was observed. The UPV test results indicated that the Quality of concrete was "Good" in various members, which were exposed to the fire.

The equivalent cube compressive strength assessment results of concrete core samples extracted from various members in fire damaged area were found to be satisfying the M25 grade of concrete, which was used in construction of building. The depth of carbonation assessed on various core samples extracted from identified locations indicated that the carbonation depth was $0 \mathrm{~mm}$ in $8 \mathrm{RCC}$ members and $10 \mathrm{~mm}$ in one column in the lift lobby. The average cover thickness in various tested members was found to be $35 \mathrm{~mm}$ to $45 \mathrm{~mm}$ in slab soffit, $35 \mathrm{~mm}$ to $42 \mathrm{~mm}$ in columns and $35 \mathrm{~mm}$ in beams. These cover thickness values qualifies for fire resistance of 2 hours as per criteria for Nominal Cover to Meet Specified Period of Fire Resistance as given in Table-16A of IS 456:2000. The results of chemical analysis covering chloride content, sulphate content and $\mathrm{pH}$ value were found to be within the permissible limits as prescribed in IS: 456 2000.

The microscopic investigation of the fire damaged cores indicated that the distribution pattern of the grains and pores spaces changed drastically. Even the morphology of the grains of the fine aggregate component was also changed. Large variation was noticed in air void distribution pattern from the bottom to top portion of the roof. Bottom portion was directly exposed to fire, which had caused sealed walled air voids bigger in size. Size of pores after fire might have increased but have very stable and firm walls, which had presently helped to achieve more strength to the concrete. As the tracking of microscopic analysis gone inside the core, size of air voids reduced drastically. However, partial melting of fine aggregate component was noticed in these areas. All these features have improved the cohesiveness of the concrete. Microscopic study also established that there was appreciable increase in the strength of the concrete cores. This had been concluded based on the features of the matrix at the different levels of the cores. This observation was found to be similar in the samples. The fire had damaged least in the top part of the total structure.

\section{Recommended repair and rehabilitation measures}

Based on the results of various studies as discussed above, the authors suggested indigenously available state of art materials, specifications and technique for effective repair and rehabilitation of fire affected members of building. The suggested repair procedure included. 
i) Removal of all cracked and loose cement plaster from the Reinforced Cement Concrete members and walls in fire damaged area by chiseling out surface concrete up to $20 \mathrm{~mm}$ depth in deteriorated structural elements and to remove the existing plaster over the wall also.

ii) Applying bond coat of SBR (Styrene Butadiene Rubber) latex based polymer modified cement slurry in proportions 1:1 (1 cement: 1 polymer) to be applied on the prepared surfaces of concrete/substrate.

iii) To rehabilitate roof slab soffit, Columns and Beams by building up the profile of structural members up to $40 \mathrm{~mm}$ average depth \& $20 \mathrm{~mm}$ average thickness in walls by Polymer Modified Mortar (PMM) using emulsified SBR latex conforming to ASTM C1059 (2013) Type-I in damaged areas (1 Cement-3 part graded cleaned river sand +15 $\%$ latex by weight of cement) with $0.35 \mathrm{w} / \mathrm{c}$ ratio, in $10-15 \mathrm{~mm}$ thick layers by applying bond coat between successive/each layers including leveling and profiling complete. Proper curing to be done for the repair work. Gunny bags to be used for effective curing. Polypropylene fibres to be added to reduce shrinkage.

\section{Conclusion}

- Field investigation on various representative samples of concrete members indicated 'Good' Quality of concrete, this was also supported by observed ample concrete cover thicknesses and strength of concrete was found to be more than required strength of M25 grade of concrete.

- Comparison of compositional changes in the surface concrete $(0-20 \mathrm{~mm})$ and subsurface concrete (beyond $20 \mathrm{~mm}$ ) samples as observed in X-Ray diffraction and DTA studies indicated that the surface concrete in Slabs, Beams \& Columns in fire damaged area were subjected to a temperature of about $750^{\circ} \mathrm{C}$ but sub-surface strata beneath $20 \mathrm{~mm}$ remained unaffected.

- Based on the various investigation studies, it was suggested that the concrete portion directly exposed to the fire should be removed by chiseling to the depth up to which the damage was observed and building up profile by applying system of SBR Bond coat \& PMM to compensate for damaged surface concrete in fire exposed concrete elements.

\section{References}

ACI (1986). Guide for the Use of Polymer in Concrete. Committee 548. Joumal of the American Concrete Institute, 83(5), 798-829.

ACI (1997). Standard method for determining fire resistance of concrete and masonry construction assemblies. Detroit, American Concrete Institute Committee.

Ali, F., Nadjai, A., Silcock, G., \& Abu-Tair, A. (2004). Outcomes of a major research on fire resistance of concrete columns. Fire safety journal, 39(6), 433-445.

ASTM C1059 (2013) Standard Specification for Latex Agents for Bonding Fresh To Hardened Concrete.

Bailey, C. (2002). Holistic behaviour of concrete buildings in fire. Proceedings of the Institution of Civil Engineers-Structures and Buildings, 152(3), 199-212.

Buchanan, A. H., \& Abu, A. K. (2017). Structural design for fire safety. John Wiley \& Sons.

Capote, J. A., Alvear, D., Lázaro, M., Espina, P., Fletcher, I. A., Welch, S., \& Torero, J. L. (2006). Analysis of thermal fields generated by natural fires on the structural elements of tall buildings, Proceedings, Int. Cong. Fire Safety in Tall Buildings, Santander, Spain, pp. 93-109. 
CEN (2003). Design of concrete structures-Part 1-2: General rules-Structural fire design. European Committee for Standardization, EN 1992 Eurocode 2.

Chan, Y. N., Peng, G. F., \& Anson, M. (1999). Residual strength and pore structure of high-strength concrete and normal strength concrete after exposure to high temperatures. Cement and concrete composites, 21(1), 23-27.

FIB(2008). Fire design of concrete structures - structural behaviour and assessment, The International Federation for Structural Concrete, State-of-art report, Bulletin No. 46.

Fletcher, I. A., Welch, S., Torero, J. L., Carvel, R. O., \& Usmani, A. (2007). Behaviour of concrete structures in fire. Thermal science, 11(2), 37-52.

Georgali, B., \& Tsakiridis, P. E. (2005). Microstructure of fire-damaged concrete. A case study. Cement and Concrete composites, 27(2), 255-259.

Hertz, K. D. (2004). Reinforcement data for fire safety design. Magazine of Concrete Research, 56(8), $453-$ 459.

Hertz, K. D. (2005). Concrete strength for fire safety design. Magazine of concrete research, 57(8), 445453.

Hertz, K. D., \& Sørensen, L. S. (2005). Test method for spalling of fire exposed concrete. Fire safety journal, $40(5), 466-476$.

Ingham, J. P. (2007). Assessment of fire-damaged concrete and masonry structures: the application of petrography. Proceedings of the 11th Euroseminar on Microscopy Applied to Building Materials, $1-16$.

IS: 13311 (1992). Non Destructive Testing of Concrete - Methods of Test, Part - I Ultrasonic Pulse Velocity

IS: 456 (2000). Indian Standard for Plain and Reinforced Concrete - Code of Practice

IS: 516 (1959). Methods of tests for strength of concrete

ISO (1975). Fire Resistance Tests. Elements of Building Construction, ISO 834, International Organization for Standardization. Geneva,

Pathak, R. P., Munzni, B. K., Sharma, P., Mahure, N. V., Vyas, S., \& Ratnam, M. (2013). Estimation of Fire Damage to Concrete Structure: A Case Study. International Journal of Engineering, 2(4), 130-136.

Sangluaia, C., Haridharan, M. K., Natarajan, C., \& Rajaraman, A. (2013). Behaviour of reinforced concrete slab subjected to fire. Int. J. Comput. Eng. Res, 3(1), 195-206.

Schneider, U. (1988). Concrete at high temperatures - a general review. Fire safety journal, 13(1), 55-68.

Stawiski, B. (2005). The Use of Nondestructive Methods in Postfire Diagnostics. KKBN, Zakopane, 23-28.

Usmani, A. S., Rotter, J. M., Lamont, S., Sanad, A. M., \& Gillie, M. (2001). Fundamental principles of structural behaviour under thermal effects. Fire safety journal, 36(8), 721-744.

Yehia, S., \& Kashwani, G. (2013). Performance of Structures Exposed to Extreme High Temperature-An Overview, Open Journal of Civil Engineering, 3(3), 154-161 